\title{
Eosinophilic pneumonia and respiratory failure associated with venlafaxine treatment
}

\author{
M.C. Fleisch ${ }^{\#}$, F. Blauer ${ }^{\#}$, J.G.H. Gubler ${ }^{\#}$, M. Kuhn ${ }^{+}$, T.A. Scherer*
}

Eosinophilic pneumonia and respiratory failure associated with venlafaxine treatment. M.C. Fleisch, F. Blauer, J.G.H. Gubler, M. Kuhn, T.A.Scherer. (C) ERS Journals Ltd 2000. ABSTRACT: Drugs are well known causes of eosinophilic lung disease. In many patients, symptoms increase slowly, pulmonary infiltrates and eosinophilia progress over weeks, and resolve upon withdrawal of the offending agent.

Rarely, the disease presents like acute eosinophilic pneumonia with acute onset of symptoms and rapidly progressing infiltrates which may be associated with respiratory failure.

This report describe a case of venlafaxine-induced acute eosinophilic pneumonia causing respiratory insufficiency that rapidly resolved upon institution of corticosteroid treatment.

This 5-hydroxytryptamine and noradrenaline reuptake inhibitor was previously not known to cause lung or peripheral blood eosinophilia. Considering the increasing use of this class of medication physicians have to be aware of this life-threatening and fully reversible complication.

Eur Respir J 2000; 15: 205-208.

\begin{abstract}
*Division of Pulmonary Diseases ${ }^{\#}$ Dept of Internal Medicine, Triemli Hospital, Zurich, Switzerland ${ }^{+}$Swiss Drug Monitoring Centre, Chur, Switzerland
\end{abstract}

Correspondence: T.A. Scherer, LungenZentrum Hirslanden, Witellikerstrasse 36 8008 Zürich, Switzerland. Fax: 4113872255

Keywords: Adverse effects drug hypersensitivity pulmonary eosinophilia 5-hydroxytryptamine uptake inhibitors

Received: March 191998

Accepted after revision November 71998
Drug reactions rank highly among the causes of pulmonary infiltrates with blood and/or alveolar eosinophilia [1]. In many cases, drug-induced eosinophilic lung disease presents with transient eosinophilic infiltrates that disappear after discontinuation of the drug. Some patients, however, experience a fulminant, acute eosinophilic pneumonia-like disease, and require corticosteroid treatment. Acute eosinophilic pneumonia (AEP) differs from chronic eosinophilic pneumonia (CEP) in several important aspects. The onset is within a few days, may lead to respiratory failure, and it usually does not recur after discontinuing corticosteroid treatment $[1,2]$. CEP has an insidious onset, responds promptly to corticosteroids, but the relapse rate after discontinuing treatment is quite high, although most patients are eventually able to come off corticosteroids [3]. This report describes a case with acute eosinophilic lung disease, resembling AEP, associated with venlafaxine treatment, a new antidepressant with 5-hydroxytryptamine and noradrenaline reuptake inhibiting actions [4].

\section{Case report}

A 41-yr-old Caucasian male was transferred from another hospital because of fever up to $38.9^{\circ} \mathrm{C}$, increasing shortness of breath, dry cough, chest pain, and myalgias, which had occurred over the previous 2 days.

Because of major depression he had been admitted to the psychiatry department 3 weeks prior to transfer to the authors' hospital. Five days after admission to psychiatric treatment, venlafaxine was started at a dose of $37.5 \mathrm{mg}$ daily for 9 days and $75 \mathrm{mg}$ daily for the following 8 days. He was put on no other medication.

He had stopped smoking 8 yrs previously but restarted 2 weeks prior to admission (total of 8 pack-years) and took 3-4 glasses of beer per day. He had never consumed illicit drugs, had no allergies, and had not visited a foreign country during the previous 5 yrs. He worked as a dentist in private practice.

On admission, the patient was in moderate respiratory distress, with a blood pressure of $170 / 100 \mathrm{mmHg}$, a heart rate of 112 beats per minute, and a respiratory rate of 30 breaths per minute. On examination he had bibasilar crackles and rales and dullness to percussion with otherwise normal findings. An arterial blood gas analysis on room air revealed a oxygen tension in arterial blood $\left(\mathrm{Pa}_{\mathrm{a}} \mathrm{O}_{2}\right)$ of 7.0 $\mathrm{kPa}$, a carbon dioxide tension in arterial blood $\left(\mathrm{Pa}_{\mathrm{a}} \mathrm{CO}_{2}\right)$ of $4.77 \mathrm{kPa}$, a $\mathrm{pH}$ of 7.48 , and an oxygen saturation of $89.4 \%$. Except for a white blood cell count of $19.7 \times 10^{3} \cdot \mathrm{mm}^{-3}$ with $32.5 \%$ bands and $1 \%$ eosinophils and a C-reactive protein of $239 \mathrm{mg} \cdot \mathrm{L}^{-1}$ (normal: $<3 \mathrm{mg} \cdot \mathrm{L}^{-1}$ ) laboratory results including human immunodeficiency virus (HIV) testing, serological screening for vasculitis (autoantibodies to deoxyribonucleic acid (DNA), double stranded DNA, proteinase 3, myeloperoxidase, rheumatoid factor, and circulating immune complexes) and various pulmonary pathogens (Strongyloides stercoralis, Toxocara canis, Schinococcus species, and Tricheinella spiralis), urinalysis, and stool tests for ova and parasites were normal. Total serum immunoglobulin (Ig)E was $5 \mathrm{kU} \cdot \mathrm{L}^{-1}$ (within normal limits).

A chest radiograph revealed bilateral interstitial infiltrates with prominent Kerley B lines and airspace opacities in the right lower lung field (fig. 1). 


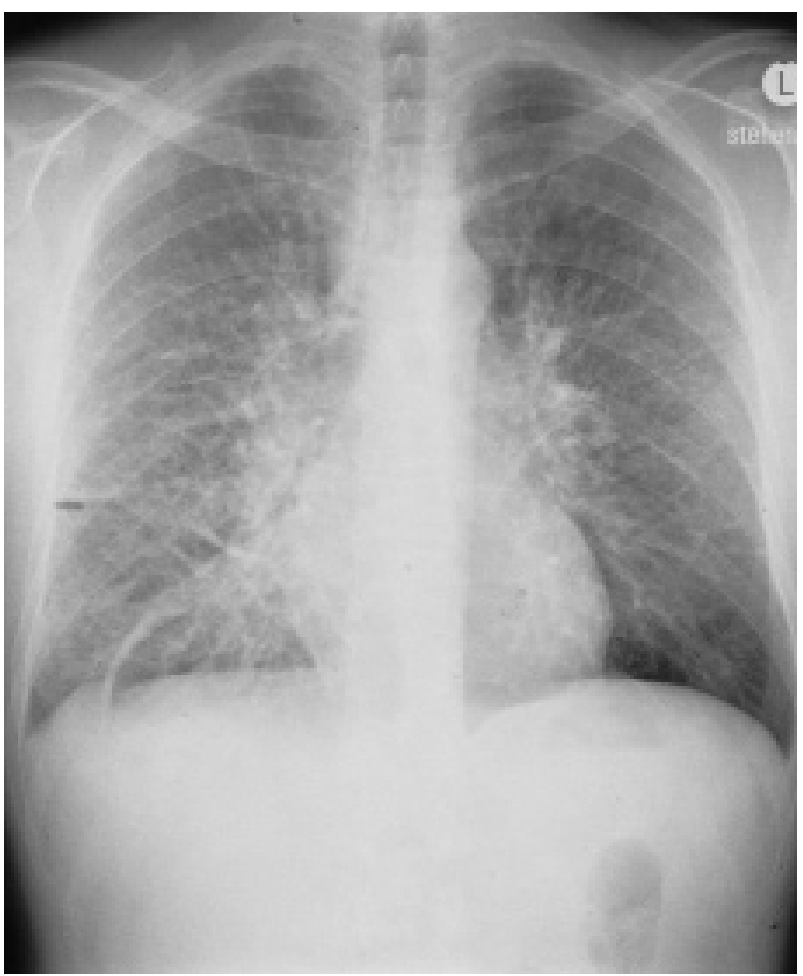

Fig. 1. - Chest radiography on admission with bilateral interstitial and right lower lobe airspace opacities. The heart and pulmonary circulation are normal.

The patient was admitted to the intensive care unit and underwent bronchoscopy. The bronchi appeared inflamed and contained increased secretions. Gram stain and cultures of the bronchial washings did not reveal any infectious organism and cytological examination showed $30 \%$ eosinophils. Treatment with high dose corticosteroids (i.v. methylprednisolone $1000 \mathrm{mg}$ per day for 3 days) and clarithromycin $500 \mathrm{mg}$ p.o. b.i.d was instituted.

A computed tomographic (CT) scan of the chest 3 days after admission disclosed patchy areas of ground-glass attenuation accentuated in both upper lung fields, thickened interlobular septae, and bilateral pleural effusions (fig. 2). The following day bronchoscopy with bronchoalveolar lavage (BAL) and transbronchial biopsy was performed. Total cell count on BAL was 177 cells. $\mu \mathrm{L}^{-1}$ with $25 \%$ eosinophils, $7 \%$ neutrophils, $57 \%$ macrophages, and 10\% lymphocytes. Transbronchial biopsies revealed an accumulation of eosinophils and neutrophils within alveolar vessels and intra-alveolar accumulation of eosinophils, macrophages, and neutrophils (fig. 3). No bronchiolitis, intra-alveolar fibrous tissue plugs, granulomas, vasculitis, virus-associated changes, or fibrosis were detected. Special stains and cultures for mycobacteria, Pneumocystis carinii, fungi, Legionella pneumophila, clamydia, and mycoplasma were negative. On tapering doses of corticosteroids the patient improved and remained afebrile after the third hospital day. The chest radiograph cleared markedly within 5 days of steroid treatment. Clarithromycin was stopped after 7 days of treatment. Pulmonary function tests (PFT) 9 days after admission showed a moderate restrictive ventilatory de-

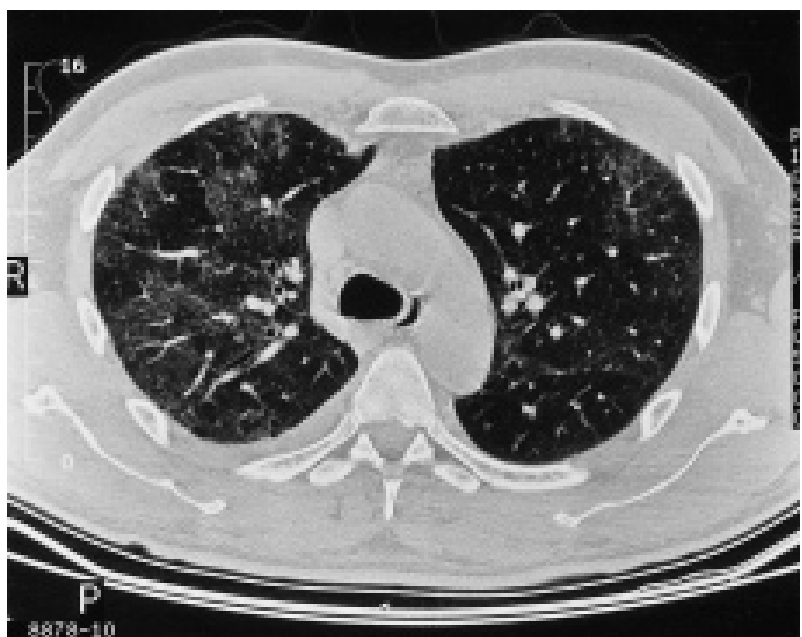

Fig. 2. - Computed tomography scan at the level of the upper lobes 3 days after admission, showing bilateral patchy areas of ground-glass attenuation and prominent interstitial markings.

fect with a vital capacity (VC) of $3.47 \mathrm{~L}$ (71\% predicted), an FEV1 of $2.76 \mathrm{~L}$ ( $72 \%$ predicted), a total lung capacity (TLC) of $4.81 \mathrm{~L}$ (70\% predicted), and a residual volume (RV) of $1.34 \mathrm{~L}$ (68\% predicted).

The patient was discharged 10 days after admission. Follow-up examinations 1 and 3 weeks after discharge revealed normal laboratory results and a normal chest radiograph. The prednisone was discontinued after 4 weeks. PFT 1 week after discharge showed some residual restriction with a VC of $4.08 \mathrm{~L}$ (84\% predicted), an FEV1 of $3.2 \mathrm{~L} \mathrm{(83 \%}$ predicted), a TLC of $5.58 \mathrm{~L}$ ( $81 \%$ predicted), and an RV of $1.5 \mathrm{~L}(77 \%$ predicted $)$.

Five months after discharge the patient was examined in the authors' emergency room for signs of upper respiratory tract infection with cough and increased sputum production. The chest radiograph had remained normal and his symptoms disappeared within 6 days of symptomatic treatment. Eleven months after discharge the patient was contacted by phone. He had resumed his work as a dentist 2 months after discharge, was free of respiratory symptoms, continued to smoke, and was later put on trazodone without adverse effects.

\section{Discussion}

Acute eosinophilic pneumonia is a recently described disease entity [2] and involves acute onset of symptoms within $\leq 5-7$ days, fever $\geq 37.2^{\circ} \mathrm{C}$, hypoxaemia, bilateral alveolar or mixed alveolar and interstitial infiltrates, and lung eosinophilia (BAL cell differential $\geq 25 \%$ eosinophils and/or predominance of eosinophils in open lung biopsy), without any history of hypersensitivity to drugs, no evidence of infection, and no other known cause of eosinophilic lung disease $[1,5]$. The histopathological features are characterized by diffuse alveolar damage with interstitial and alveolar eosinophils [6]. Radiological examination reveals diffuse interstitial and acinar opacities, ground-glass attenuation, and pleural effusion. 


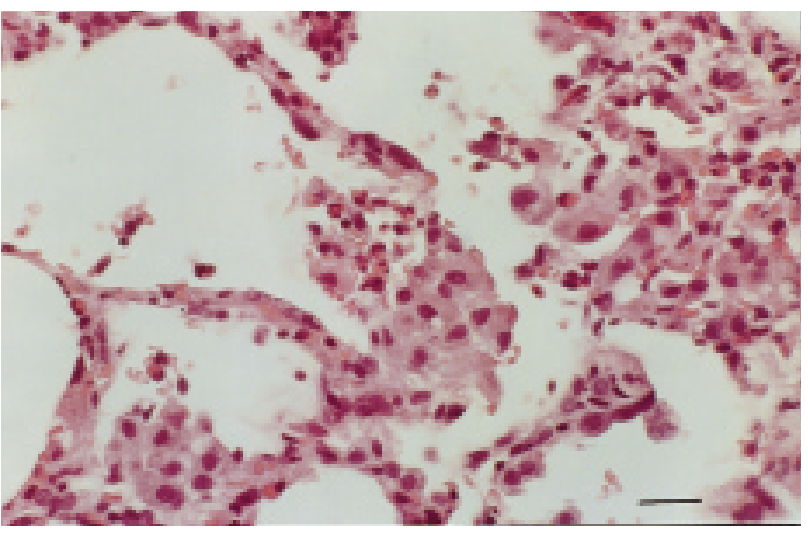

Fig. 3. - Transbronchial lung biopsy showing accumulation of eosinophils and neutrophils within alveolar vessels, and of eosinophils,

With BAL, a diagnosis can easily be established and should be performed in cases with respiratory failure, even if the peripheral blood eosinophil count is normal. In the largest published series only $5 / 15$ patients had an increased peripheral blood eosinophil count [5]. Although many patients with respiratory failure due to AEP receive corticosteroids with prompt improvement of symptoms, spontaneous resolution even of severe symptoms after withdrawal of the offending agent is possible [7, 8].

Eosinophilic lung disease can have many causes [9-12] and drug reactions are among the most frequent ones. The clinical presentation is variable, ranging from almost asymptomatic transient eosinophilic infiltrates to acute respiratory failure requiring mechanical ventilation. The disease onset of the presented case closely resembles AEP. Acute onset of symptoms within 5-7 days has previously only been described for trazodone, a 5-hydroxytryptaminereuptake inhibitor [13], minocycline [7, 8], ampicillin [14], acetaminophen [15], nitrofurantoin [16], pyrimethaminesulphadoxine [17], inhalation of 1, 1, 1-trichloroethane [18], and freebase cocaine [19]. With some precaution isotretinoine $P \mathrm{a}, \mathrm{O}_{2}(10.3 \mathrm{kPa})$ [20], iohexol (no fever) [21], and tosufloxacin tosilate [22] have to be added to this list.

TAZELAAR et al. [6] suggest less stringent criteria for the diagnosis of AEP. Cases with a duration of symptoms of $\leq 5$ days and those between 5-21 days demonstrated identical lung pathology. Using the criteria of TAZELAAR et al. [6], sulphasalazine [23], tenidap [24], diclofenac [25], carbamazepine [26], and chloroquine [27] have to be included. Methotrexate [11], granulocyte-macrophage colonystimulating factor (GM-CSF) [28], piroxicam [29], and heroin can also cause acute eosinophilic lung disease, but the reported disease presentations do not completely fulfil the criteria of AlLEN et al. [2] or TAZELAAR et al. [6] criteria (lack of information about fever and unilateral infiltrate in GM-CSF).

Pulmonary complications related to 5-hydroxytryptamine reuptake inhibitors are uncommon. Except for trazodone, no reports are available in the literature. Interestingly, the patient was later put on trazodone and tolerated it without adverse effects, which means that his lung disease was not a class effect of the 5-hydroxytryptamine reuptake inhibitors.

This is the first report about venlafaxine induced eosinophilic lung disease. Considering the increasing use of antidepressants, it is important that physicians are aware of this rare, potentially life-threatening, fully reversible complication.

\begin{abstract}
Acknowledgements. The authors thank B. Bosch and F, Bannwart, from the Institute of Pathology, Stadtspital Triemli, Zürich, Switzerland for their help in preparing the reprints of the pathology slides.
\end{abstract}

\section{References}

1. Allen JN, Davis WB. Eosinophilic lung disease. Am J Respir Crit Care Med 1994; 150: 1423-1438.

2. Allen JN, Pacht ER, Gadek JE, Davis WB. Acute eosinophilic pneumonia as a reversible cause of noninfectious respiratory failure. $N$ Engl J Med 1989; 321: 569-574.

3. Carrington CB, Addington WW, Goff AM, Madoff IMM, Schwaber JR, Gaensler EA. Chronic eosinophilic pneumonia. N Engl J Med 1969; 280: 787-798.

4. Andrews JM, Ninan PT, Nemeroff CB. Venlafaxine: a novel antidepressant that has dual mechanism of action. Depression 1996; 4: 48-56.

5. Pope-Harman AL, Davis WB, Allen ED, Christoforidis AJ, Allen JN. Acute eosinophilic pneumonia. A summary of 15 cases and review of the literature. Medicine (Baltimore) 1996; 75: 334-342.

6. Tazelaar HD, Linz LJ, Colby TV, Myers JL, Limper AH. Acute eosinophilic pneumonia: histopathologic findings in nine patients. Am J Respir Crit Care Med 1997; 155: 296-302.

7. Bentur L, Bar-Kana Y, Livni E, et al. Severe minocyclineinduced eosinophilic pneumonia: extrapulmonary manifestations and the use of in vitro immunoassays. Ann Pharmacother 1997; 31: 733-735.

8. Sitbon O, Bidel N, Dussopt C, et al. Minocycline pneumonitis and eosinophilia. A report on eight patients. Arch Intern Med 1994; 154: 1633-1640.

9. Taki R, Sawada M, Isogai S, et al. A possible role of cigarette smoking in the pathogenesis of acute eosinophilic pneumonia. Am J Respir Crit Care Med 1996; 153: A271.

10. Löffler W. Zur differentialdiagnose der lungeninfiltrierungen: über flüchtige succedan-infiltrate (mit eosinophilie). Beitr Klin Tuberk 1932; 79: 368-392.

11. Allen JN, Davis WB, Pacht ER. Diagnostic significance of increased bronchoalveolar lavage fluid eosinophils. Am Rev Respir Dis 1990; 142: 642-647.

12. Foucher P, Biour M, Blayac JP, et al. Drugs that may injure the respiratory system. Eur Respir J 1997; 10: 265279.

13. Salerno SM, Strong JS, Roth BJ, Sakata V. Eosinophilic pneumonia and respiratory failure associated with a trazodone overdose. Am J Respir Crit Care Med 1995; 152: 2170-2172.

14. Poe RH, Condemi JJ, Weinstein SS, Schuster RJ. Adult respiratory distress syndrome related to ampicillin sensitivity. Chest 1980; 77: 449-451.

15. Kondo K, Inoue Y, Harnada HY, Kohno N, Hiwada K. Acetaminophen-induced eosinophilic pneumonia. Chest 1993; 104: 291-292.

16. Sovijärvi ARA, Lemola M, Stenius B, IndänpäänHeikkilä J. Nitrofurantoin-induced acute, subacute, and 
chronic pulmonary reactions. Scand J Respir Dis 1977; 58: 41-50.

17. McCormack D, Morgan WKC. Fansidar hypersensitivity pneumonitis. Br J Dis Chest 1987; 81: 194-196.

18. Kelly KJ, Ruffing R. Acute eosinophilic pneumonia following intentional inhalation of Scotchguard. Ann Allergy 1993; 71: 358-361.

19. Oh PI, Balter MS. Cocaine induced eosinophilic lung disease. Thorax 1991; 47: 478-479.

20. Oliviero G, Constans P, Caby I, De Rohan CP, Lacherade JC. Pneumopathie induite par l'isotretinone. Rev Mal Respir 1995; 12: 631-633.

21. Jennings CA, Deveikis J, Azumi N, Yeager H. Eosinophilic pneumonia associated with reaction to radiographic contrast medium. South Med J 1991; 84: 92-95.

22. Kimura N, Miyazaki E, Matsuno O, Abe Y, Tsuda T. Drug-induced pneumonitis with eosinophilic infiltration due to tosufloxacin tosilate. Nihon Kokyuki Gakkai Zasshi 1998; 36: 618-622.

23. Timmer R, Duurkens VAM, van Hees P.A.M. Sulpha- salazine-induced eosinophilic pneumonia. Neth $\mathrm{J}$ Med 1992; 41: 153-157.

24. Martinez BM, Domingo P. Acute eosinophilic pneumonia associated with tenidap. BMJ 1997; 314: 349.

25. Khalil H, Molinary E, Stoller JK. Diclofenac (Voltaren)induced eosinophilic pneumonitis. Arch Intern Med 1993; 153: 1649-1652.

26. de Vriese ASP, Philippe J, van Rentgerhem DM, et al. Carbarnazepine hypersensitivity syndrome: Report of 4 cases and review ofthe literature. Medicine (Baltimore) 1995; 74: 144-151.

27. Coëtmeur D, Guivarch GBE, Lopes C. Pneumopathie eosinophilique aigue. Role possible de la chloroquine. Rev Mal Respir 1998; 15: 657-660.

28. Seebach J, Speich R, Fehr J, Tuchschmid P, Russi E. GMCSF-induced acute eosinophilic pneumonia. $\mathrm{Br} J \mathrm{Hae}-$ matol 1995; 90: 963-965.

29. Pfitzenmeyer P, Meier M, Zuck P, et al. Piroxicam induced pulmonary infiltrates and eosinophilia. $J$ Rheumatol 1994; 21: 1573-1577. 